\title{
Reconsolidation of Human Memory: Brain Mechanisms and Clinical Relevance
}

\author{
Lars Schwabe, Karim Nader, and Jens C. Pruessner
}

The processes of memory formation and storage are complex and highly dynamic. Once memories are consolidated, they are not necessarily fixed but can be changed long after storage. In particular, seemingly stable memories may re-enter an unstable state when they are retrieved, from which they must be re-stabilized during a process known as reconsolidation. During reconsolidation, memories are susceptible to modifications again, thus providing an opportunity to update seemingly stable memories. While initial demonstrations of memory reconsolidation came mainly from animal studies, evidence for reconsolidation in humans is now accumulating as well. Here, we review recent advances in our understanding of human memory reconsolidation. After a summary of findings on the reconsolidation of human fear and episodic memory, we focus particularly on recent neuroimaging data that provide first insights into how reconsolidation processes are implemented in the human brain. Finally, we discuss the implications of memory modifications during reconsolidation for the treatment of mental disorders such as posttraumatic stress disorder and drug addiction.

Key Words: Amygdala, drug addiction, episodic memory, fear memory, hippocampus, memory reconsolidation, PTSD

A berrant memory processes are a hallmark of many mental disorders. One of the most prominent examples illustrating the role of dysfunctional memories in psychopathology is found in posttraumatic stress disorder (PTSD), where individuals experience unwanted memories through nightmares, flashbacks, or intrusive recollections of a traumatic event (1). However, maladaptive memories are also common in other disorders. Patients with panic disorder or obsessive-compulsive disorder, for instance, often show a memory bias toward threat-related information (2). Moreover, drug addiction has been interpreted as an usurpation of systems of associative memory underlying reward-related learning (3). Altering such dysfunctional memories is a crucial step in the successful treatment of these and other mental disorders.

For more than a century, it was generally assumed that freshly acquired memories are initially in a dynamic, labile state for a short period of time, after which the memory is fixed or consolidated. Consolidated memories were thought to be persistent and insensitive to disruption (4). However, this classical consolidation view has been challenged over the past 15 years by accumulating evidence showing that the retrieval (or reactivation) of consolidated memories returns memories to a labile state. These reactivated memories then need to undergo a process of restabilization, called reconsolidation, to be preserved [for reviews, see $(5,6)]$. During reconsolidation, memories can be strengthened, weakened, or updated (Figure 1), thus providing an opportunity to modify seemingly stable memories, even for memories that are decades old.

In this review, we focus on memory reconsolidation in humans and, in particular, on how reconsolidation processes are implemented in the human brain. After a concise (and admittedly

From the Department of Cognitive Psychology (LS), Ruhr-University Bochum, Bochum, Germany; and Department of Psychology (KN, $J C P)$ and Douglas Mental Health Institute and Department of Psychiatry (JCP), McGill University, Montreal, Canada.

Address correspondence to Lars Schwabe, Ph.D., Ruhr-University Bochum, Department of Cognitive Psychology, Universitaetsstrasse 150, Bochum 44780, Germany; E-mail: Lars.Schwabe@ruhr-uni-bochum.de. selective) review of the most important reconsolidation findings in animals [see $(5,6)$ for more comprehensive reviews of reconsolidation in animals], we first summarize data on reconsolidation processes in human fear and episodic memory. We then focus on recent neuroimaging studies that provide insight into the neural processes underlying reconsolidation in the human brain. Finally, we discuss the potential relevance of memory reconsolidation manipulations in the treatment of mental disorders such as PTSD and drug addiction.

\section{Memory Reconsolidation: Nothing Is Written in Stone}

The idea that memories may re-enter a vulnerable state after their retrieval is not at all new. Already in the 1960s, it was shown that electroconvulsive shock, an amnesic treatment, resulted in memory loss if administered immediately after retrieval or reinstatement of a seemingly robust passive-avoidance memory $(7,8)$. Similar findings were reported in the following years $(9,10)$. These data were interpreted as evidence for a distinction between inactive, invulnerable memory traces wired into the brain and active memory traces that were open to disruption, irrespective of the time since encoding (11). What was initially called cue-dependent amnesia $(9,10)$ and later referred to as reconsolidation $(12,13)$, however, was considered by many as an anomaly. The Zeitgeist seemed to favor the view of a unidirectional stabilization process during which memories progress gradually from unstable to stable and thus become fixed and resistant to change $(14,15)$. This consolidation view dominated the neuroscience of memory for several more decades to come.

It was only at the end of the past century that the reconsolidation phenomenon was rediscovered by showing amnesic effects of pharmacologic interventions after reactivation of seemingly stable memories [reviewed in (16)]. In 2000, reconsolidation was ultimately returned to the spotlight of memory research by a study that demonstrated a reconsolidation process in the (lateral and basal) amygdala for consolidated auditory fear memory, a well described task at the systems level of analyses (17). In this study, rats were injected into the amygdala with the protein synthesis inhibitor anisomycin, an amnesic agent, after they were reminded of a conditioning session that took place 24 hours or 2 weeks before. Rats treated with anisomycin showed intact postreactivation short-term memory but impaired postreactivation long-term memory. Importantly, animals that were not reminded of the conditioning session before anisomycin 


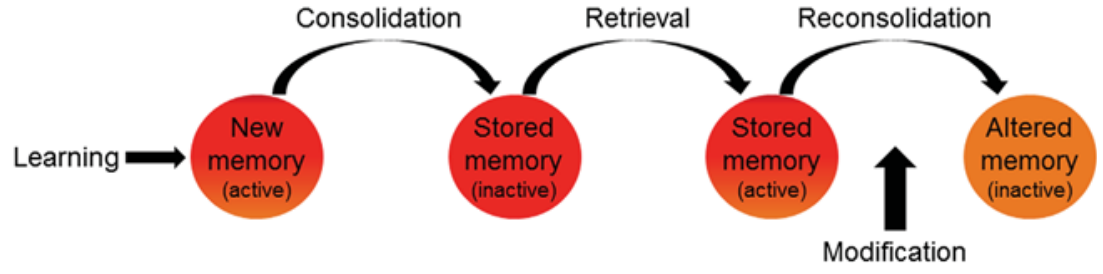

Figure 1. The reconsolidation concept. Shortly after learning, a memory is in an active state until it gets consolidated. The retrieval of a consolidated memory returns the memory from an inactive state to an active state again, from which it needs to be stabilized anew. The process during which reactivated memories are stabilized again is called reconsolidation. During reconsolidation, the active memory traces are vulnerable to modifications. administration had intact memory. This was suggestive of the notion that it was indeed the reactivation that rendered the fear memory labile again. Moreover, if the anisomycin treatment was delayed by 6 hours after reactivation, it had no effect on memory, suggesting that the reactivation-induced instability was also transient. Shortly after this seminal study, other studies using systemic anisomycin injections showed similar effects (18) but added that de novo protein synthesis is also required in the hippocampus after reactivation of a hippocampus-dependent contextual fear memory (19). Beyond the behavioral level of analysis, there is also evidence for a cellular process akin to reconsolidation. In particular, it has been shown that synaptic reactivation by test pulses destabilizes pathways that have undergone late long-term potentiation (20). In addition, reconsolidation blockade has been shown to reverse the molecular changes induced by learning (21), demonstrating the specificity of its impairment.

To date, the majority of the studies on reconsolidation have been done in animals $(5,6,22,23)$. Although these animal studies provide important insights into the mechanisms involved in reconsolidation and into how these differ from those underlying consolidation $(18,24)$, to assess the practical relevance of reconsolidation, whether in the classroom or in the clinic, it is crucial to demonstrate reconsolidation in humans. First, modern evidence for reconsolidation in humans came a few years after the rebirth of interest in reconsolidation from a study showing that learning of a new motor sequence after reactivation of a previously learned sequence reduced the subsequent memory for the original sequence (25). The last few years, however, have seen an accumulating body of data demonstrating reconsolidation in human memory and the growth in human reconsolidation studies has been exponential $(23,26)$. We will briefly review the findings on reconsolidation of human fear and episodic memory, before we focus on the underlying processes in the human brain as revealed by recent neuroimaging studies.

\section{Reconsolidation of Human Fear Memory}

Based on the findings in rodents demonstrating that conditioned fear memory can be changed when reactivated (17), researchers sought to target the reconsolidation of fear memory in humans. A first study on the reconsolidation of human fear memory (27) capitalized on the well-known role of adrenergic receptors for emotional memory (28). In this study, healthy participants were first fear-conditioned and the fear was reactivated by a single presentation of a conditioned stimulus 24 hours later. Shortly before reactivation, participants received the beta blocker propranolol, blocking beta-adrenergic receptors during the proposed reconsolidation window. Beta-adrenergic receptor blockade during and after reactivation impaired the fear memory 24 hours later and prevented the return of fear in a reinstatement protocol. Importantly, propranolol without reactivation did not alter fear memory, showing that the reactivation was required to render the fear memory vulnerable again. Propranolol can disrupt the reconsolidation of fear memory even when the fear acquisition is pharmacologically enhanced. Furthermore, the effect of the beta blocker remains if it is administered after reactivation, thus ruling out the possibility that propranolol affects fear reactivation rather than reconsolidation (29). Using an instructed fear paradigm, it was shown that propranolol also reduces the subjective feeling of anxiety of an aversive event that was actually never experienced (30). There is, however, evidence that retrieval per se is not sufficient to initiate the reconsolidation of fear memories. For fear memory labilization to occur, new information has to be presented during reactivation $(31,32)$. Moreover, whereas propranolol during reconsolidation alters specific measures of fear such as the startle response, it does not appear to affect declarative fear memory or other conditioning parameters such as skin conductance $(27,33)$. The latter and specific methodological issues, such as the fact that propranolol was often administered before memory reactivation, raised some skepticism about whether the observed effects of propranolol may indeed be attributed to altered reconsolidation processes [(34) but see (35) for a reply].

An alternative way of modifying fear memories during reconsolidation is the combination of fear reactivation and extinction learning, as demonstrated by previous rodent studies (36). There is first evidence that this procedure might indeed be successful. Participants who underwent extinction training 10 minutes after the reactivation of a previously acquired conditioned fear showed no recovery of fear in a re-extinction session 24 hours and up to 1 year later (37). Later studies replicated that postreactivation extinction prevents the return of fear and that the blockade of fear is specific to the reactivated stimulus (38-40). Others, however, found no indication that a single reminder before extinction training could diminish fear memory (41-43). These discrepancies might at least partly be due to procedural differences, for example, in the conditioned stimuli, the reinforcement schedules during fear acquisition, or the use of online unconditioned stimulus-expectancy ratings (44). Thus, although the extinction protocol has the advantage that it is noninvasive and safe, the robustness of its effects in humans is unclear at this point.

\section{Reconsolidation of Human Episodic Memory}

The malleability of episodic memories long after encoding has been widely accepted in cognitive psychology $(45,46)$. However, the role of reconsolidation processes in the modification of episodic long-term memory traces has been addressed only rather recently. In an elegant set of experiments (47), participants learned a list of objects on day 1. Twenty-four hours later, half of the subjects received a reminder, and then all subjects learned a second list of objects. Memory for the original list was tested again 24 hours later. Results showed that only participants who were reminded of the first list before new learning incorporated 
objects from the second list into their memory of the first list. This effect was found in the test on day 3, but not immediately after new learning, suggesting that the modification of memory was reactivation-dependent and that a timedependent, consolidation-like process was at work. Similar effects were reported for paired associate memory (48) or more real-life related material, such as a movie of a terrorist attack (49). Followup studies suggested that the spatial context triggers the reconsolidation of episodic memories (50) and further demonstrated that the observed changes of memory after reactivation were due to updating of the original memory and not to source confusion [(51), see also (49)].

New learning after reactivation may not only update but can also impair existing episodic memories $(49,52,53)$. Interestingly, in addition to memory for artificial material learned in the laboratory, people's autobiographic memories also may be susceptible to impairing effects of new learning during reconsolidation (54), underlining the relevance of this phenomenon for memory in everyday life. However, if memory reactivation is not followed immediately by learning of interfering material, it may serve to strengthen episodic memories (55). Stressful experiences after memory reactivation can also affect subsequent retention. Yet, the direction of these effects is not entirely clear, as some studies showed enhanced $(56,57)$ and others showed impaired memory (58) when participants were stressed after retrieval, which might be owing to differences in the learning material or the learningreactivation interval.

Beyond these behavioral modifications of episodic memory reconsolidation and in line with early animal experiments $(7,8)$, recent evidence shows that electroconvulsive shock after memory reactivation may interfere with the reconsolidation of human episodic memories (59). Moreover, pharmacologic manipulations were also used to modify memory during reconsolidation. For instance, beta-adrenergic receptor blockade by propranolol before the retrieval of previously learned neutral and emotional pictures was shown to reduce the subjective feeling of vivid remembering that is usually associated with emotional memories (60). Glucose or a gamma-aminobutyric acidergic agonist after reactivation, however, enhanced later retention of paired associations $(57,61)$. In sum, there is by now striking evidence that episodic memories can be updated, strengthened, or weakened after their retrieval, i.e., during reconsolidation.

\section{Reconsolidation in the Human Brain}

How is the reconsolidation of fear or episodic memories represented in the human brain? The first study that addressed this question employed the superior memory for emotional relative to neutral information (62). It is well established that this emotional memory enhancement is owing to arousal-related noradrenergic activity in the amygdala $(63,64)$, and it has been shown that the administration of the beta-adrenergic receptor antagonist propranolol shortly after learning blocks the enhanced consolidation of emotional material (65). To test whether propranolol may also interfere with the reconsolidation of emotional memories, participants were first presented neutral and emotionally arousing pictures. On the following day, the memory for these pictures was reactivated (or not) after participants had ingested propranolol or a placebo. Recognition memory performance was tested again 24 hours later. Critically, brain activity was recorded using functional magnetic resonance imaging (fMRI) both during reactivation and during memory testing. The behavioral data showed that propranolol indeed abolished the emotional memory enhancement when it was administered before memory reactivation. Propranolol without reactivation or reactivation without propranolol, however, had no effect on the strength of the emotional memories. Neuroimaging revealed that memory reactivation was associated with significant activation of hippocampus and amygdala, areas that are known to play a key role in emotional memory formation and retrieval $(28,64)$. Importantly, the placebo + reactivation and propranolol + reactivation groups did not differ in brain activity during reactivation, suggesting that the beta blocker alone did not interfere with the reactivation of the memory traces; although, it cannot be ruled out that the drug altered other reactivation parameters than those that are detectable by fMRI. During memory testing 24 hours later, participants who had received propranolol before reactivation showed increased hippocampus and amygdala activation, indicating that these structures needed to be more strongly activated to enable correct memory (hits) for emotional stimuli.

Another recent fMRI study examined the neural correlates of the attenuation of consolidated fear memories by extinction after reactivation (39). Similar to the study described above (37), participants in this study were first fear-conditioned. The fear was then reactivated 24 hours later and participants underwent an extinction session either 10 minutes or 6 hours after reactivation, i.e., within or outside the proposed reconsolidation window. Fear memory was assessed in a renewal test on the following day and in a reinstatement test 3 days after reactivation. Corroborating previous behavioral data (37), extinction training after reactivation prevented the return of fear in the 10-minute group but not in the 6-hour group. Brain activity during renewal showed reduced activation of the amygdala, a key locus of fear acquisition and retrieval $(66,67)$, in participants who received the extinction session shortly after fear memory reactivation compared with those who underwent the extinction session after a 6-hour delay. Interestingly, amygdala activity during renewal was also associated with the return of fear during the reinstatement test (particularly in the 6-hour group). Further evidence indicates that the ventromedial prefrontal cortex (vmPFC) plays an important role in the effect of extinction training after fear memory reactivation. In particular, extinction training after fear memory reactivation diminished $v m P F C$ involvement and also reduced vmPFC-amygdala coupling, which might enable extinction learning training to more persistently change the original fear-memory trace within the amygdala (68).

Whereas fMRI studies provide only correlational data, recent studies using transcranial magnetic stimulation (TMS) allow conclusions about brain areas playing a causal role in memory reconsolidation. One such study examined modifications of motor memories after reactivation (69). Here, participants were trained in a sequential finger-tapping task and performed a memory test (reactivation session) 30 minutes thereafter. During reactivation, TMS was applied over area M1 in an attempt to interfere with memory reconsolidation, or participants received sham stimulation. Performance in a memory test 24 hours later showed that TMS during reactivation reduced the motor memory improvement from reactivation to test significantly. This detrimental effect on motor memory was accompanied by reduced activation of the supplementary motor area, an area that is critical for the implementation of motor actions (70). However, the reactivated motor memories were most likely not yet fully consolidated and the design of this study did not allow assessing whether the memory modifications were reactivation-dependent. Another TMS study used a design that circumvented these shortcomings. 
In this study, the right lateral prefrontal cortex, a brain area that is crucial for memory reactivation (71), was stimulated via TMS after the reactivation of episodic memories. The results of this study showed that TMS of the prefrontal cortex enhanced memory recall 24 hours later. Critically, this memory enhancing effect occurred only when TMS was preceded by memory reactivation and when TMS was applied shortly $(<1$ hour) after reactivation (72).

Although there are important differences between these studies, for example, with respect to the type of memory tested or the manipulations used, together these studies suggest, at a general level, that during reactivation more or less the same areas are recruited that are involved in initial memory formation. Manipulations after reactivation then change the activity of these areas and these changes are linked to alterations in subsequent memory performance.

\section{Changing Memories after Reactivation: Clinical Perspectives and Boundary Conditions}

The ability to modify established emotional memories has important implications for the treatment of many mental disorders, including anxiety disorders, such as PTSD, and addiction, as demonstrated by initial clinical studies in the 1960s (73). In PTSD, the strength of trauma memory can be considered the result of the overconsolidation of the memory for the traumatic event due to the action of stress hormones, such as glucocorticoids and noradrenaline, that are released in response to the traumatic experience (74). These hormones are well known to promote the formation of lasting memories $(4,28)$. Therefore, one approach to treat traumatic memories is to block the action of stress hormones after a potentially traumatic event has happened, to interfere with its consolidation. There is some evidence that this strategy might indeed be successful $[(75,76)$, but see also (77)]. For instance, patients treated with the beta-adrenergic receptor antagonist propranolol shortly after a vehicle accident were less likely to develop PTSD symptoms in the following 3 months compared with patients who had received a placebo (75). Memory formation, however, can be modulated only within a relatively short time window after an experience, during which most individuals do not have access to clinical treatment. This is where reconsolidation comes into play. If memories are susceptible to modifications again after retrieval, this may provide a second window of opportunity to alter trauma memories. First studies have been following this approach. Patients with chronic PTSD, for example, were asked to prepare a personal traumatic script, addressing the traumatic experience that caused the PTSD (78). Each patient then received either propranolol or a placebo. One week later, all patients underwent a psychophysiological script-driven imagery procedure. The results showed that psychophysiological responding during mental imagery of the traumatic event was significantly lower in patients who had received propranolol a week earlier than in patients who were administered a placebo. These findings were replicated and extended in three open-label studies (79). Although these studies lacked the appropriate control groups that would be required to conclude that the observed effects are due to changes in memory reconsolidation, these findings suggest that postretrieval manipulations might be a promising tool in the treatment of PTSD, even when the trauma is decades old.

Preclinical studies indicate that the reconsolidation of drugrelated memories also can be disrupted and suggest that disruption of drug memory reconsolidation may represent a treatment strategy for addiction (80). Drug addiction is a progressive psychopathology that leads to compulsive drugtaking behavior. Even after long periods of drug abstinence, relapse is quite common (81). Cues in the environment that have acquired an associative relationship with the drugs are thought to contribute to drug taking and relapse (80). There are at least three properties of cues associated with drugs that could contribute to drug-taking behavior: they can acquire rewarding and reinforcing properties onto themselves, they can induce the resumption of drug-taking behavior (relapse), and they increase craving for the drug $(82,83)$. These cue-drug associations are very persistent and resistant to the extinction protocols used to decrease the strength of these conditioned responses in humans (84) or animals (85).

Animal models of drug addiction have reported that the neurobiological mechanisms of wanting undergo reconsolidation. Blocking wanting can reduce the ability of substance-related cues to induce relapse. Consequently, targeting reconsolidation of the mechanisms that mediate drug wanting should increase the likelihood of long-term abstinence in humans (80). For example, infusion of zif268 antisense oligodeoxynucleotides into the basolateral amygdala shortly before the reactivation of a previously acquired conditioned stimulus-cocaine association abolished the reinforcing properties of this drug-related cue (86). Likewise, propranolol after reactivation can disrupt the reinforcing properties of an appetitively reinforced conditioned stimulus (87). The translation of these findings to humans, however, has been difficult. Postreactivation stress or propranolol were shown to impair the reconsolidation of drug-related words in abstinent heroin addicts $(88,89)$. Yet, changes in craving or relapse to drug taking were not reported in these studies. Only very recently, it was demonstrated that reconsolidation manipulations may alter addictive behaviors in humans (90). Building on studies showing the efficacy of postreactivation extinction training in reducing fear memories $(36,37)$, heroin addicts were exposed briefly to neutral or heroin-related cues and then received an interference by a new learning paradigm. This amnesic intervention led to reduced cue-induced craving and reduced physiological responding to heroin cues up to 6 months later. However, control groups showed no effect. Many additional studies are required to follow this initial study to determine whether reconsolidation modifications will be a successful strategy to treat addiction in humans.

Both in PTSD and in addiction, as in any other disorder, unwanted memories need to be destabilized before they can be modified during reconsolidation. Reconsolidation, however, is no universal phenomenon. Several boundary conditions have been identified under which memories that would normally undergo reconsolidation do not. For example, it has been proposed that older and stronger memories are less likely to be modified after reactivation than younger and weaker ones (91-94). If memory age and strength are boundary conditions for reconsolidation, this would have major implications for reconsolidation-based treatment approaches of PTSD. Further boundary conditions that have been suggested are the reminder structure (95), the context in which the reactivation takes place (50), the frequency of memory reactivations (96), or the presence of new information at reactivation $(31,32)$ that specifically targets existing memories (49). However, several of these boundary conditions were found in some studies but not in others (6). For example, age and strength boundary conditions appear to be less relevant for the reconsolidation of drug memories (86). Moreover, there is evidence that boundary conditions themselves may be transient and that they can be overcome (93,97-99). Nevertheless, 
understanding exactly when memories undergo reconsolidation and when they do not is critical for any attempts to use reconsolidation manipulations as a treatment strategy for mental disorders.

\section{Summary}

Starting from its rediscovery at the end of the past century, reconsolidation has been the topic of intense scientific inquiry. Animal studies provided important insights into the molecular and cellular basis of reconsolidation (100). Reconsolidation of human memory has by now been demonstrated repeatedly and across different tasks. First evidence points to a potential use of reconsolidation manipulations in the treatment of disorders such as PTSD and addiction and, most recently, neuroimaging has been used to explore the mechanisms underlying reconsolidation in the human brain. Yet, a number of important questions remain. Are all individuals similarly susceptible to postreactivation modifications of memory? And if not, what factors can account for interindividual differences in reconsolidation? How long is the reconsolidation window and can its duration be influenced? How does the nature of the reconsolidation process determine whether memory is weakened, strengthened, or otherwise updated? How are the reconsolidation process and its boundary conditions represented in the human brain? Are postreactivation modifications of fear, trauma, or drug memories really long lasting? These and related questions need to be addressed to enhance our understanding of the reconsolidation phenomenon and, in particular, its value in the treatment of aberrant memory processes in mental disorders.

All authors report no biomedical financial interests or potential conflicts of interest.

1. American Psychiatric Association (2013): Diagnostic and Statistical Manual of Mental Disorders: DSM-V. Washington, DC: American Psychiatric Press.

2. Coles ME, Heimberg RG (2002): Memory biases in the anxiety disorders: Current status. Clin Psychol Rev 22:587-627.

3. Hyman SE, Malenka RC, Nestler EJ (2006): Neural mechanisms of addiction: The role of reward-related learning and memory. Annu Rev Neurosci 29:565-598.

4. McGaugh J (2000): Memory-a century of consolidation. Science 287: $248-251$.

5. Lee JLC (2009): Reconsolidation: Maintaining memory relevance. Trends Neurosci 32:413-420.

6. Nader K, Hardt O (2009): A single standard for memory: The case for reconsolidation. Nat Rev Neurosci 10:224-234.

7. Misanin JR, Miller RR, Lewis DJ (1968): Retrograde amnesia produced by electroconvulsive shock after reactivation of a consolidated memory trace. Science 160:554-555.

8. Schneider AM, Sherman W (1968): Amnesia: A function of the temporal relation of foot-shock to electroconvulsive shock. Science 159:219-221.

9. Lewis DJ, Bregman NJ (1973): Source of cues for cue-dependent amnesia in rats. J Comp Physiol Psychol 85:421-426.

10. Lewis DJ, Bregman NJ, Mahan J (1972): Cue-dependent amnesia in rats. J Comp Physiol Psychol 81:243-247.

11. Lewis DJ (1979): Psychobiology of active and inactive memory. Psychol Bull 86:1054-1083.

12. Spear N (1973): Retrieval of memory in animals. Psychol Rev 80: 163-194.

13. Przybyslawski J, Sara SJ (1997): Reconsolidation of memory after its reactivation. Behav Brain Res 84:241-246.

14. McGaugh JL (1966): Time-dependent processes in memory storage. Science 153:1351-1359.

15. Glickman S (1961): Preservative neural processes and consolidation of the memory trace. Psychol Bull 58:218-233.
16. Sara SJ (2000): Retrieval and reconsolidation: Toward a neurobiology of remembering. Learn Mem 7:73-84.

17. Nader K, Schafe GE, LeDoux JE (2000): Fear memories require protein synthesis in the amygdala for reconsolidation after retrieval. Nature 406:722-726.

18. Taubenfeld SM, Milekic MH, Monti B, Alberini CM (2001): The consolidation of new but not reactivated memory requires hippocampal C/EBP $\beta$. Nat Neurosci 4:813-818.

19. Debiec J, LeDoux JE, Nader K (2002): Cellular and systems reconsolidation in the hippocampus. Neuron 36:527-538.

20. Fonseca R, Nagerl UV, Bonhoeffer T (2006): Neuronal activity determines the protein synthesis dependence of long-term potentiation. Nat Neurosci 9:478-480.

21. Rose JK, Rankin CH (2006): Blocking memory reconsolidation reverses memory-associated changes in glutamate receptor expression. J Neurosci 26:11582-11587.

22. Dudai Y (2012): The restless engram: Consolidations never end. Annu Rev Neurosci 35:227-247.

23. Finnie PSB, Nader K (2012): The role of metaplasticity mechanisms in regulating memory destabilization and reconsolidation. Neurosci Biobehav Rev 36:1667-1707.

24. Lee JLC, Everitt BJ, Thomas KL (2004): Independent cellular processes for hippocampal memory consolidation and reconsolidation. Science 304:839-843.

25. Walker MP, Brakefield T, Hobson JA, Stickgold R (2003): Dissociable stages of human memory consolidation and reconsolidation. Nature 425:616-620.

26. Besnard A, Caboche J, Laroche S (2012): Reconsolidation of memory: A decade of debate. Prog Neurobiol 99:61-80.

27. Kindt M, Soeter M, Vervliet B (2009): Beyond extinction: Erasing human fear responses and preventing the return of fear. Nat Neurosci 12:256-258

28. McGaugh JL (2004): The amygdala modulates the consolidation of memories of emotionally arousing experiences. Annu Rev Neurosci 27:1-28.

29. Soeter M, Kindt M (2012): Stimulation of the noradrenergic system during memory formation impairs extinction learning but not the disruption of reconsolidation. Neuropsychopharmacology 37: 1204-1215.

30. Soeter M, Kindt M (2012): Erasing fear for an imagined threat event. Psychoneuroendocrinology 37:1769-1779.

31. Sevenster D, Beckers T, Kindt M (2013): Prediction error governs pharmacologically induced amnesia for learned fear. Science 339: 830-833.

32. Sevenster D, Beckers T, Kindt M (2012): Retrieval per se is not sufficient to trigger reconsolidation of human fear memory. Neurobiol Learn Mem 97:338-345.

33. Soeter M, Kindt M (2010): Dissociating response systems: Erasing fear from memory. Neurobiol Learn Mem 94:30-41.

34. Schiller D, Phelps EA (2011): Does reconsolidation occur in humans? Front Behav Neurosci 5:24.

35. Brunet A, Ashbaugh AR, Saumier D, Nelson M, Pitman RK, Tremblay J, et al. (2011): Does reconsolidation occur in humans: A reply. Front Behav Neurosci 5:74.

36. Monfils MH, Cowansage KK, Klann E, LeDoux JE (2009): Extinctionreconsolidation boundaries: Key to persistent attenuation of fear memories. Science 324:951-955.

37. Schiller D, Monfils MH, Raio CM, Johnson DC, LeDoux JE, Phelps EA (2010): Preventing the return of fear in humans using reconsolidation update mechanisms. Nature 463:49-53.

38. Oyarzun JP, Lopez-Barroso D, Fuentemilla L, Cucurell D, Pedraza C, Rodriguez-Fornells A, de Diego-Balaguer R (2012): Updating fearful memories with extinction training during reconsolidation: A human study using auditory aversive stimuli. PLoS One 7:e38849.

39. Agren T, Engman J, Frick A, Björkstrand J, Larsson E-M, Furmark T, Fredrikson M (2012): Disruption of reconsolidation erases a fear memory trace in the human amygdala. Science 337:1550-1552.

40. Agren T, Furmark T, Eriksson E, Fredrikson M (2012): Human fear reconsolidation and allelic differences in serotonergic and dopaminergic genes. Transl Psychiatry 2:e76.

41. Soeter M, Kindt M (2011): Disrupting reconsolidation: Pharmacological and behavioral manipulations. Learn Mem 18:357-366. 
42. Kindt M, Soeter M (2013): Reconsolidation in a human fear conditioning study: A test of extinction as updating mechanism. Biol Psychol 92:43-50.

43. Golkar A, Bellander M, Olsson A, Ohman A (2012): Are fear memories erasable?-reconsolidation of learned fear with fear-relevant and fearirrelevant stimuli. Front Behav Neurosci 6:80.

44. Warren NT, Anderson KM, Kwon C, Bosshardt L, Jovanovic T, Bradley B, Norrholm SD (2013): Human fear extinction and return of fear using reconsolidation update mechanisms: The contribution of online expectancy ratings [published online ahead of print October 29]. Neurobiol Learn Mem.

45. Loftus EF (2005): Planting misinformation in the human mind: A 30year investigation of the malleability of memory. Learn Mem 12: 361-366.

46. Fischhoff B (1975): Hindsight is not equal to foresight: The effect of outcome knowledge on judgment. J Exp Psychol Hum Percept Perform 1:288-299.

47. Hupbach A, Gomez R, Hardt O, Nadel L (2007): Reconsolidation of episodic memories: A subtle reminder triggers integration of new information. Learn Mem 14:47-53.

48. Forcato C, Rodriguez ML, Pedreira ME, Maldonado H (2010): Reconsolidation in humans opens up declarative memory to the entrance of new information. Neurobiol Learn Mem 93:77-84.

49. Chan JC, LaPaglia JA (2013): Impairing existing declarative memory in humans. Proc Natl Acad Sci U S A 110:9309-9313.

50. Hupbach A, Hardt O, Gomez R, Nadel L (2008): The dynamics of memory: Context-dependent updating. Learn Mem 15:574-579.

51. Hupbach A, Gomez R, Nadel L (2009): Episodic memory reconsolidation: Updating or source confusion? Memory 17:502-510.

52. Strange BA, Kroes MC, Fan JE, Dolan RJ (2010): Emotion causes targeted forgetting of established memories. Front Behav Neurosci 4: 175 .

53. Forcato C, Burgos VL, Argibay PF, Molina VA, Pedreira ME, Maldonado H (2007): Reconsolidation of declarative memory in humans. Learn Mem 14:295-303.

54. Schwabe L, Wolf OT (2009): New episodic learning interferes with the reconsolidation of autobiographical memories. PLoS One 4: e7519.

55. Forcato C, Rodriguez ML, Pedreira ME (2011): Repeated labilizationreconsolidation processes strengthen declarative memory in humans. PLoS One 6:e23305.

56. Coccoz V, Maldonado H, Delorenzi A (2011): The enhancement of reconsolidation with a naturalistic mild stressor improves the expression of a declarative memory in humans. Neuroscience 185: $61-72$.

57. Coccoz V, Sandoval AV, Stehberg J, Delorenzi A (2013): The temporal dynamics of enhancing a human declarative memory during reconsolidation. Neuroscience 246:397-408.

58. Schwabe L, Wolf OT (2010): Stress impairs the reconsolidation of autobiographical memories. Neurobiol Learn Mem 94:153-157.

59. Kroes MCW, Tendolkar I, van Wingen GA, van Waarde JA, Strange BA, Fernandez G (2014): An electroconvulsive therapy procedure impairs reconsolidation of episodic memories in humans. Nat Neurosci 17: 204-206.

60. Schwabe L, Nader K, Pruessner JC (2013): Beta-adrenergic blockade during reactivation reduces the subjective feeling of remembering associated with emotional episodic memories. Biol Psychol 92: 227-232.

61. Rodriguez ML, Campos J, Forcato C, Leiquarda R, Maldonado $H$, Molina VA, Pedreira ME (2013): Enhancing a declarative memory in humans: The effect of clonazepam on reconsolidation. Neuropharmacology 64:432-442.

62. Schwabe L, Nader K, Wolf OT, Beaudry T, Pruessner JC (2012): Neural signature of reconsolidation impairments by propranolol in humans. Biol Psychiatry 71:380-386.

63. Cahill L, Babinsky R, Markowitsch HJ, McGaugh JL (1995): The amygdala and emotional memory. Nature 377:295-296.

64. Cahill L, McGaugh JL (1998): Mechanisms of emotional arousal and lasting declarative memory. Trends Neurosci 21:294-299.

65. Cahill L, Prins B, Weber M, McGaugh JL (1994): Beta-adrenergic activation and memory for emotional events. Nature 371:702-704.
66. LaBar KS, Gatenby JC, Gore JC, LeDoux JE, Phelps EA (1998): Human amygdala activation during conditioned fear acquisition and extinction: A mixed-trial fMRI study. Neuron 20:937-945.

67. Büchel C, Morris J, Dolan RJ, Friston KJ (1998): Brain systems mediating aversive conditioning: An event-related fMRI study. Neuron 20:947-957.

68. Schiller D, Kanen JW, LeDoux JE, Monfils MH, Phelps EA (2013): Extinction during reconsolidation of threat memory diminishes prefrontal cortex involvement. Proc Natl Acad Sci U S A 110: 20040-20045.

69. Censor N, Dayan E, Cohen LG (2013): Cortico-subcortical neuronal circuitry associated with reconsolidation of human procedural memories [published online ahead of print June 15]. Cortex.

70. Gerloff C, Corwell B, Chen R, Hallett M, Cohen LG (1997): Stimulation over the human supplementary motor area interferes with the organization of future elements in complex motor sequences. Brain 120:1587-1602.

71. Diekelmann S, Büchel C, Born J, Rasch B (2011): Labile or stabile: Opposing consequences for memory when reactivated during waking and sleep. Nat Neurosci 14:381-386.

72. Sandrini M, Censor N, Mishoe J, Cohen LG (2013): Causal role of prefrontal cortex in strengthening of episodic memories through reconsolidation. Curr Biol 23:2181-2184.

73. Rubin RD, Fried R, Franks CM (1968): New applications of ECT. In: Rubin RD, Franks CM, editors. Advances in Behavior Therapy. New York: Academic Press.

74. Pitman RK (1989): Post-traumatic stress disorder, hormones, and memory. Biol Psychiatry 26:221-223.

75. Pitman RK, Sanders KM, Zusman RM, Healy AR, Cheema F, Lasko NB, et al. (2002): Pilot study of secondary prevention of posttraumatic stress disorder with propranolol. Biol Psychiatry 51:189-192.

76. Vaiva G, Ducrocq F, Jezequel K, Averland B, Lestavel P, Brunet A, Marmar CR (2003): Immediate treatment with propranolol decreases posttraumatic stress disorder two months after trauma. Biol Psychiatry 54:947-949.

77. McGhee L, Maani CV, Garza TH, DeSocio PA, Gaylord KM, Black IH (2009): The effect of propranolol on posttraumatic stress disorder in burned service members. J Burn Care Res 30:92-97.

78. Brunet A, Orr SP, Tremblay J, Robertson K, Nader K, Pitman RK (2008): Effect of post-retrieval propranolol on psychophysiologic responding during subsequent script-driven traumatic imagery in post-traumatic stress disorder. J Psychiatr Res 42:503-506.

79. Brunet A, Poundja J, Tremblay J, Bui E, Thomas E, Orr SP, et al. (2011): Trauma reactivation under the influence of propranolol decreases posttraumatic stress symptoms and disorder: 3 open-label trials. $J$ Clin Psychopharmacol 31:547-550.

80. Taylor JR, Olausson P, Qiunn JJ, Torregrossa MM (2009): Targeting extinction and reconsolidation mechanisms to combat the impact of drug cues on addiction. Neuropharmacology 56(suppl 1):186-195.

81. Gawin FH, Kleber HD (1986): Abstinence symptomatology and psychiatric diagnosis in cocaine abusers. Clinical observations. Arch Gen Psychiatry 43:107-113.

82. de Wit H, Stewart J (1981): Reinstatement of cocaine-reinforced responding in the rat. Psychopharmacology (Berl) 75:134-143.

83. Robbins TW, Cador M, Taylor JR, Everitt BJ (1989): Limbic-striatal interactions in reward-related processes. Neurosci Biobehav Rev 13: $155-162$.

84. Conklin CA, Tiffany ST (2002): Applying extinction research and theory to cue-exposure addiction treatments. Addiction 97:155-167.

85. Crombag HS, Shaham Y (2002): Renewal of drug seeking by contextual cues after prolonged extinction in rats. Behav Neurosci 116:169-173.

86. Lee JLC, Di Ciano P, Thomas KL, Everitt BJ (2005): Disrupting reconsolidation of drug memories reduces cocaine-seeking behavior. Neuron 47:795-801.

87. Milton AL, Lee JLC, Everitt BJ (2008): Reconsolidation of appetitive memories for both neutral and drug reinforcement is dependent on \{beta\}-adrenergic receptors. Learn Mem 15:88-92.

88. Zhao LY, Sun LL, Shi J, Li P, Zhang Y, Lu L (2011): Effects of $\beta$ adrenergic receptor blockade on drug-related memory reconsolidation in abstinent heroin addicts. Drug Alcohol Depend 118:224-229. 
89. Zhao LY, Zhang XL, Shi J, Epstein DH, Lu L (2009): Psychosocial stress after reactivation of drug-related memory impairs later recall in abstinent heroin addicts. Psychopharmacology (Berl) 203:599-608.

90. Xue YX, Luo YX, Wu P, Shi HS, Xue LF, Chen C, et al. (2012): A memory retrieval-extinction procedure to prevent drug craving and relapse. Science 336:241-245.

91. Milekic M, Alberini CM (2002): Temporally graded requirement for protein synthesis following memory reactivation. Neuron 36: 521-525.

92. Suzuki A, Josselyn SA, Frankland PW, Masushige S, Silva AJ, Kida S (2004): Memory reconsolidation and extinction have distinct temporal and biochemical signatures. J Neurosci 24:4787-4795.

93. Wang SH, de Oliveira Alvares L, Nader K (2009): Cellular and systems mechanisms of memory strength as a constraint on auditory fear reconsolidation. Nat Neurosci 12:905-912.

94. Wichert S, Wolf OT, Schwabe L (2011): Reactivation, interference, and reconsolidation: Are recent and remote memories likewise susceptible? Behav Neurosci 125:699-704.
95. Forcato C, Argibay PF, Pedreira ME, Maldonado H (2009): Human reconsolidation does not always occur when a memory is retrieved: The relevance of the reminder structure. Neurobiol Learn Mem 91: 50-57.

96. Wichert S, Wolf OT, Schwabe L (2013): Changing memories after reactivation: A one-time opportunity? Neurobiol Learn Mem 99:38-49.

97. Wichert S, Wolf OT, Schwabe L (2013): Updating of episodic memories depends on the strength of new learning after memory reactivation. Behav Neurosci 127:331-338.

98. Bustos SG, Giachero M, Maldonado H, Molina VA (2010): Previous stress attenuates the susceptibility to Midazolam's disruptive effect on fear memory reconsolidation: Influence of pre-reactivation Dcycloserine administration. Neuropsychopharmacology 35:1097-1108.

99. Winters BD, Tucci MC, DaCosta-Furtado M (2009): Older and stronger object memories are selectively destabilized by reactivation in the presence of new information. Learn Mem 16:545-553.

100. Tronson NC, Taylor JR (2007): Molecular mechanisms of memory reconsolidation. Nat Rev Neurosci 8:262-275. 